\title{
Pharmacogenomic Evaluation of the Antidepressant Citalopram in the Mouse Tail Suspension Test
}

\author{
James J Crowley', Edward S Brodkin², Julie A Blendy', Wade H Berrettini ${ }^{1,2}$ and Irwin Lucki*,1,2 \\ 'Department of Pharmacology, University of Pennsylvania, Philadelphia, PA, USA; ${ }^{2}$ Department of Psychiatry, University of Pennsylvania, \\ Philadelphia, PA, USA
}

\begin{abstract}
The identification of genetic variants regulating antidepressant response in human patients would allow for more individualized, rational, and successful drug treatments. We have previously identified the BALB/c) inbred mouse strain as highly responsive to the selective serotonin reuptake inhibitor (SSRI) citalopram in the tail suspension test (TST), a widely used and well-established screening paradigm for detecting compounds with antidepressant activity. In contrast, $\mathrm{A} /$ J mice did not show a significant response to citalopram in this test despite exposure to equivalent plasma levels of the drug. To identify genetic determinants of this differential response, $506 F_{2}$ mice from an intercross between BALB/CJ and $A / J$ mice were phenotyped. Composite interval mapping of 92 mice from the phenotypic extremes revealed three loci on chromosomes 7, 12, and 19 affecting citalopram response in the TST. The quantitative trait locus (QTL) at the telomeric end of chromosome 19 showed the greatest level of significance. Three candidate genes residing in this locus include those for vesicular monoamine transporter 2 (VMAT2, slc/8a2), alpha 2A adrenergic receptor (adra2a), and beta I adrenergic receptor (adrb /). The protein coding regions of these three genes in $B A L B / c$ J and $A / J$ mice were sequenced and two polymorphisms were found in VMAT2 (Leul I7Pro and Ser505Pro), while the transcribed regions of adra2a and adrb / were of identical sequence between strains. Follow-up studies are needed to determine if the VMAT2 polymorphisms are functional and if they could explain the chromosome 19 QTL. The present quantitative trait study suggests possible candidate genes for human pharmacogenetic studies of therapeutic responses to SSRIs such as citalopram.
\end{abstract}

Neuropsychopharmacology (2006) 31, 2433-2442. doi: I 0. I 038/sj.npp. I 30 I065; published online 22 March 2006

Keywords: depression; citalopram; SSRI; genetics; QTL; serotonin

\section{INTRODUCTION}

Selective serotonin (5-HT) reuptake inhibitors (SSRIs) are the most frequently prescribed medications for the treatment of depression, although approximately $40 \%$ of patients do not have an adequate therapeutic response to initial SSRI treatment (Nelson, 1999). An individual's responses to an SSRI, including both therapeutic and adverse reactions, are complex traits, each of which is likely influenced by variants of many genes. Using genetic information to identify patients that are most likely to respond to a particular antidepressant would allow for more rational drug treatment that could improve overall therapeutic efficacy by matching individual patients to the best treatments. Several polymorphisms have been associated with SSRI response in humans, including genetic variants of the 5-HT transporter,

*Correspondence: Dr I Lucki, Department of Psychiatry, University of Pennsylvania, 538 Clinical Research Building, 415 Curie Blvd., Philadelphia, PA 19104, USA, Tel: + I 215573 3305, Fax: + I 215 5732149 , E-mail: lucki@pharm.med.upenn.edu

Received 20 September 2005; revised 25 January 2006; accepted 9 February 2006

Online publication: 16 February 2006 at http://www.acnp.org/citations/ Npp02 $1606050587 /$ default.pdf
$5-\mathrm{HT}_{2 \mathrm{~A}}$ receptor, tryptophan hydroxylase, G-protein beta3 subunit, and interleukin-1beta (Serretti and Artioli, 2004).

Preclinical genetic studies, such as quantitative trait locus (QTL) analysis, may facilitate discovery of additional genetic polymorphisms predictive of SSRI response. In QTL mapping, phenotypically divergent strains are crossbred to produce hybrids, which are then intercrossed or backcrossed to produce an $\mathrm{F}_{2}$ or $\mathrm{N}_{2}$ population, respectively. Quantitative phenotypes of the $\mathrm{F}_{2}$ or $\mathrm{N}_{2}$ animals are then correlated with DNA marker genotypes to identify chromosomal regions regulating genetic variation in the phenotype (Lander and Botstein, 1989). QTL mapping has multiple advantages and disadvantages in the search for genes underlying complex traits in animal models (Flint et al, 2005). Although identification of individual genes from the chromosomal region correlated with the trait remains a challenge, modern genetic techniques and the publication of the mouse genomic structure for some inbred strains (Waterston et al, 2002) could allow more rapid identification of candidate genes.

The antidepressant response to citalopram was measured using the tail suspension test (TST), a widely used and reliable method for measuring the pharmacological effects of antidepressant drugs in mice (Cryan et al, 2002, 2005; 
Steru et al, 1985). In the TST, a mouse is suspended by the tail from an elevated bar for several minutes. Typically, the mouse immediately engages in several escape-oriented behaviors, such as leg kicks and body jerks, followed by increasing bouts of immobility. The frequency or duration of immobility is reduced by antidepressant treatments. The TST has been shown to be sensitive to an array of antidepressant treatments, including tricyclics, SSRIs, monoamine oxidase inhibitors, atypical antidepressants, and electroconvulsive therapy (Perrault et al, 1992; Steru et al, 1985, 1987; Teste et al, 1990, 1993). Inbred rodent strains show substantial variability in baseline performance and behavioral response to antidepressant administration in the TST (Bai et al, 2001; Crowley et al, 2005; Liu and Gershenfeld, 2001, 2003; Rippoll et al, 2003; for a review, see Crowley and Lucki, 2005; Cryan et al, 2005). Baseline response was not correlated with the response to antidepressants (Crowley et al, 2005; Liu and Gershenfeld, 2003), so that mice with the greatest immobility values are not necessarily the most responsive to antidepressants. In a recent survey of eight inbred strains, the $\mathrm{BALB} / \mathrm{cJ}$ inbred mouse strain was identified as highly responsive, and the $\mathrm{A} / \mathrm{J}$ strain as nonresponsive, to the antidepressant-like effects of the SSRI citalopram in the TST (Crowley et al, 2005). The responses of these strains to citalopram showed behavioral and pharmacological specificity in that BALB/cJ and $A / J$ mice responded equivalently to the effects of citalopram on locomotor activity and suppressing feeding and did not differ in baseline immobility values. Furthermore, an earlier study by our laboratory also found BALB/cJ mice to be significantly more responsive than $\mathrm{A} / \mathrm{J}$ mice to the antidepressant-like effects of the SSRI fluoxetine in the forced swim test (FST), a second test for antidepressant response (Lucki et al, 2001). Because of their diverse responses on antidepressant tests, these strains appeared to be ideal for a QTL mapping study aimed at discovering genes regulating the antidepressant response to citalopram.

In this study, QTL mapping was used to identify the chromosomal loci that contribute to the response to citalopram in the TST in BALB/cJ and A/J mice. An F2 intercross of these two strains (506 mice) was assessed for citalopram response using the TST. Those F2 mice demonstrating extreme phenotypes (the highest and lowest $9.1 \%$ ) were genotyped for 106 murine microsatellite polymorphisms. Interval mapping revealed three loci on chromosomes 7, 12, and 19 that are responsible for more than $40 \%$ of the genetic variance in citalopram response measured by the TST. Candidate gene analysis identified two mis-sense polymorphisms in the gene encoding the vesicular monoamine transporter 2 (VMAT2, slc18a2) that may explain the chromosome 19 QTL.

\section{MATERIALS AND METHODS}

\section{Subjects}

Male and female BALB/cJ and A/J mice (aged 8-12 weeks) were obtained from Jackson Laboratories (Bar Harbor, $\mathrm{ME})$ for testing in the TST and subsequent breeding. Mice were housed in groups of four per cage (cage size: $28.5 \times 17.5 \times 13.0 \mathrm{~cm})$ for at least 1 week prior to testing. Female BALB/cJ (C) and male A/J (A) mice were crossed to produce a total of $40 \mathrm{CAF}_{1}$ mice (21 male and 19 female) that were weaned at 4 weeks of age into groups of four per cage and tested in the TST after reaching 8-12 weeks of age. Several mating pairs were then set up between female and male $\mathrm{CAF}_{1}$ mice yielding a total of $506\left(\mathrm{CAF}_{1} \times \mathrm{CAF}_{1}\right) \mathrm{F} 2$ mice (253 male and 253 female) that were weaned at 4 weeks of age into groups of four per cage and tested on the TST after reaching 8-12 weeks of age. Animals were maintained in a temperature-controlled environment $\left(22 \pm 1^{\circ} \mathrm{C}\right)$ under a 12-h light-dark cycle, with lights turned on at 0700 hours. Food and water were freely available. All behavioral testing was performed between 1000 and 1800 hours. All animal procedures were in strict accordance with the NIH Guide for the Care and Use of Laboratory Animals and were approved by the Institutional Animal Care and Use Committee of the University of Pennsylvania.

\section{Drug}

Racemic citalopram hydrobromide (a generous gift of Forest Labs, New York, NY) was prepared fresh daily by dissolving the powder in deionized water. Drug was administered by intraperitoneal (i.p.) injection in a volume of $0.01 \mathrm{ml} / \mathrm{g}$ body weight and the dose was $20 \mathrm{mg} / \mathrm{kg}$ calculated as the weight of the base. The test dose was selected from a previous dose-response study (Crowley et al, 2005). Control animals received injections of $0.9 \%$ saline in a volume of $0.01 \mathrm{ml} / \mathrm{g}$.

\section{TST}

Each mouse was tested twice in the TST: once with saline and once with citalopram, 1 week apart. Preliminary studies indicated no order effects when a 1-week period was placed between tests (data not shown). Nonetheless, a counterbalanced design was used, where half of the animals received saline followed by citalopram and the other half received citalopram followed by saline. Mice were injected with drug or saline $30 \mathrm{~min}$ prior to a 6 -min tail suspension test. An automated TST device (Med Associates, St Albans, VT) was used to measure the duration of behavioral immobility. Mice were suspended by the tail with tape to a vertical aluminum bar connected to a strain gauge. Mice were positioned such that the base of their tail was aligned with the bottom of the bar. A strain gauge detected any movements by the mouse. The total duration of immobility was calculated as the time the force of the mouse's movements was below a preset threshold. An optimum threshold was determined by comparing manually scored videotapes with automated scores. The following settings were used in all experiments: threshold $1=7$, gain $=16$, time constant $=0.25$, resolution $=200 \mathrm{~ms}$. For a more detailed methodological description of the use of this automated TST device, see Crowley et al (2004).

\section{Genotyping}

Citalopram response was defined as the percent change in immobility resulting from drug treatment relative to saline treatment for each mouse (see 'Statistical Analysis' below). The $46 \mathrm{~F}_{2}$ mice with the largest and $46 \mathrm{~F}_{2}$ mice with the smallest response to citalopram were selected for 
genotyping. The phenotypic extremes of the F2 distribution were genotyped, as recommended by Lander and Botstein (1989). While the exact fraction of the extremes selected for genotyping may be influenced by many factors (eg, expense of genotyping and phenotyping), the highest and lowest $9.1 \%$ were selected because this value allowed optimal use of a 96-well plate. Genomic DNA was extracted from liver samples (Lahiri and Nurnberger, 1991) and microsatellite markers were amplified using primers developed at the Whitehead Institute/Massachusetts Institute of Technology Center for Genome Research (Cambridge, MA) and obtained from Invitrogen (Carlsbad, CA). A total of 106 microsatellite markers spaced at $\sim 20 \mathrm{cM}$ intervals across the genome (19 autosomes and the $\mathrm{X}$ chromosome) were genotyped in the $\mathrm{F}_{2}$ mice. Centimorgan positions of microsatellite markers were obtained from The Jackson Laboratory database (www.informatics.jax.org/searches/ marker_form.shtml). PCR was performed using protocols suggested by the manufacturer (Invitrogen). PCR products were run on 3-4\% Metaphor agarose gels (BioWhittaker Molecular Applications, Rockland, ME) and the bands were visualized using ethidium bromide staining and ultraviolet transillumination. Alleles were read by one of the authors (JC) and entered into a database with TST phenotypes.

\section{Candidate Gene Sequencing}

Three genes in the chromosome 19 QTL (adra2a, adrb1, and slc18a2) were selected for comparative sequence analysis of the protein coding regions. Adra $2 a$ and $a d r b 1$ are singleexon genes and were sequenced by PCR amplification of the exon and direct sequencing. Slc18a2 has a more complicated gene structure and was sequenced from RT-PCR products amplified from total RNA purified from whole mouse brain using Trizol reagent (Invitrogen, Carlsbad, $\mathrm{CA})$. DNA sequences from $\mathrm{BALB} / \mathrm{cJ}$ and $\mathrm{A} / \mathrm{J}$ mice were aligned using the basic local alignment search tool (BLAST, www.ncbi.nlm.nih.gov/blast) and protein sequences were translated with TRANSLATE (http://au.expasy.org/tools/ dna.html) and aligned using SIM (http://au.expasy.org/ tools/sim-prot.html). Sequences were obtained from both strands for all genes and complementary strands were in complete agreement.

\section{Determination of Plasma Citalopram Levels}

Mice ( $n=6$ per group) were injected with $20 \mathrm{mg} / \mathrm{kg}$ citalopram by i.p. injection and killed after 5, 30, or 120 min. Trunk blood was immediately collected into heparin-treated tubes and plasma isolated by centrifugation. Citalopram and the internal standard desipramine were extracted from mouse plasma samples using a protein precipitation extraction method. Each prepared sample was reconstituted with $200 \mu \mathrm{l}$ of $\mathrm{H}_{2} \mathrm{O}: \mathrm{MeOH}:$ AA $70: 30: 0.1$ $(\mathrm{v}: \mathrm{v}: \mathrm{v})$ before injecting onto an LC/MS/MS. Citalopram and desipramine were separated from the matrix using reverse phase HPLC, and were detected using tandem mass spectrometry in positive turbo ionspray mode. The mobile phases used were $\mathrm{H}_{2} \mathrm{O}:$ FA $100: 0.1(\mathrm{v}: \mathrm{v})$ on channel A and $\mathrm{MeOH}: \mathrm{FA} 100: 0.1(\mathrm{v}: \mathrm{v})$ on channel B. A Leap HTC PAL autosampler injected $3 \mu \mathrm{l}$ of the reconstituted sample onto a Phenomenex, Jupiter C4 $50 \times 2.0,5 \mu$ HPLC column under a flow rate of $0.5 \mathrm{ml} / \mathrm{min}$, which was supplied by Shimadzu LC-10ADvp HPLC pumps. An Applied Biosystems/Sciex API4000 mass spectrometer was used for detection of citalopram and the internal standard desipramine.

\section{Statistical Analysis}

TST performance was measured using total immobility values in $6 \mathrm{~min}$ and drug response was calculated using percent change in immobility. To calculate the percent change in immobility resulting from drug treatment for each mouse, the citalopram immobility value was divided by the saline immobility value, multiplied by 100 and subtracted by 100 . The Equality of Variances F-test was used to compare citalopram response scores among the parental inbred strains, $\mathrm{F}_{1}$ and $\mathrm{F}_{2}$ populations. The ShapiroWilk $W$-test was used to test the normality of the F2 distribution.

QTL analysis was performed using Map Manager QTX software (Manly et al, 2001). A Permutation test (with 10000 permutations) was first run to determine the likelihood ratio statistic (LRS) thresholds for suggestive, significant or highly significant QTL for our particular data set. QTX was then used to perform marker regression and interval mapping under a free regression model, yielding $\chi^{2}$ $p$-values, LRS statistics, and an estimate of the percent genetic variance between the parental strains explained by any given QTL.

\section{RESULTS}

\section{QTL Breeding and Behavioral Phenotyping}

The magnitude of response to citalopram in BALB/cJ and $\mathrm{A} / \mathrm{J}$ mice and their $\mathrm{F}_{1}$ and $\mathrm{F}_{2}$ hybrids in the TST is shown in Figure 1. ANOVA revealed significant differences in citalopram response between these four populations of mice $\left(\mathrm{F}_{(3,572)}=8.119, p<0.0001\right)$. The results of Fisher's PLSD post hoc analysis divided the populations into three significantly different $(p<0.05)$ categories (largest to smallest response): $\mathrm{BALB} / \mathrm{cJ}>\mathrm{F}_{1}=\mathrm{F}_{2}>\mathrm{A} / \mathrm{J}$. BALB/cJ mice

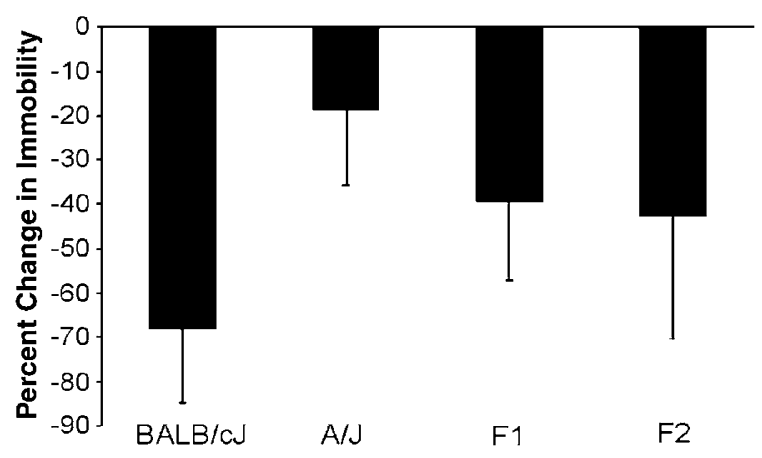

Figure I TST response to citalopram in $B A L B / C$ land $A / J$ mice and their $\mathrm{FI}$ and F2 hybrids. The percent change in immobility (mean \pm one standard deviation) resulting from treatment with $20 \mathrm{mg} / \mathrm{kg}$ citalopram is shown for populations of BALB/cJ $(n=15), \mathrm{A} / \mathrm{J}(n=15), \mathrm{FI}(n=40)$, and F2 $(n=506)$ mice. ANOVA and Fisher's PLSD post hoc analysis divided the populations into three significantly different $(p<0.05)$ categories with $B A L B / c$ the most responsive, $A / /$ the least responsive, and the $F_{1}$ and $F_{2}$ hybrids demonstrating an intermediate level of response. 
Table I Differential Variance in Citalopram Response Scores for the Parental Strains, FI and F2 Hybrids

\begin{tabular}{lccccc}
\hline Population & N & Variance & DF & F-value & p-value \\
\hline BALB/c) & 15 & 290 & 14,505 & 0.387 & 0.002 \\
A / & 15 & 292 & 14,505 & 0.372 & 0.001 \\
FI & 40 & 313 & 39,505 & 0.416 & 0.001 \\
F2 & 506 & 673 & - & - & - \\
\hline
\end{tabular}

The equality of variances $F$-test indicated that the variance in the $\mathrm{F} 2$ population is significantly greater than the variance in the $B A L B / c$ J, $A / J$, or $F /$ populations.

were significantly more responsive than $\mathrm{A} / \mathrm{J}$ mice and the $\mathrm{F}_{1}$ and $F_{2}$ hybrids demonstrated an intermediate level of response. There were, however, no significant differences in mean baseline immobility between the four groups of mice ((immobility sec \pm SEM) BALB/cJ: $140 \pm 12$; A/J: $149 \pm 14$; $\left.\mathrm{F}_{1}: 143 \pm 11 ; \mathrm{F}_{2}: 146 \pm 4 ; \mathrm{F}_{(3,572)}=0.20, p<0.70\right)$.

The $\mathrm{F}_{2}$ population of mice demonstrated a significantly greater level of variance in citalopram response scores than the $\mathrm{BALB} / \mathrm{cJ}, \mathrm{A} / \mathrm{J}$, or $\mathrm{F}_{1}$ populations (see Table 1 ), as expected for a population with greater genetic variation. Since the $\mathrm{F}_{1}$ mice are genetically homogeneous, the $\mathrm{F} 1$ variance reflects nongenetic (ie environmental, random) influences on citalopram responsiveness. The difference between the variance for the $F_{1}$ and $F_{2}$ generations reflects the additional variance due to genetic factors in the $\mathrm{F}_{2}$ population, a genetically heterogenous population. Heritability $\left(h^{2}\right)$, the proportion of phenotypic variation due to genetic factors, can be estimated by dividing the difference between the $\mathrm{F}_{1}$ and $F_{2}$ variances by the $F_{2}$ variance (Wehner et al, 2001). Thus, approximately half of the total variance $\left(h^{2}=360 /\right.$ $673=0.53)$ in this $F_{2}$ population was calculated to result from genetic factors. The $F_{1}$ and $F_{2}$ populations of mice were composed of roughly equal numbers of males and females, and a comparison of citalopram response by sex indicated no sex differences in either population (data not shown).

Figure 2 shows the distribution of citalopram response scores for $506 \mathrm{~F}_{2}$ mice treated with $20 \mathrm{mg} / \mathrm{kg}$ citalopram in the TST. The F2 distribution produced a bell-shaped curve that was approximately normal, but significantly skewed to the left, according to the Shapiro-Wilk $W$-test $(p<0.0001)$. The data, however, met the normality requirements for QTL analysis of the phenotypically extreme mice using QTX software. The 46 most responsive and 46 least responsive $F_{2}$ mice were selected for the genotyping of microsatellite markers spread evenly across the mouse genome.

\section{Plasma Citalopram Levels}

Figure 3 shows the plasma concentrations of citalopram measured in $\mathrm{BALB} / \mathrm{CJ}$ and $\mathrm{A} / \mathrm{J}$ mice at three time points $(5,30$, or $120 \mathrm{~min})$ following an i.p. injection of $20 \mathrm{mg} / \mathrm{kg}$. ANOVA failed to reveal any difference in citalopram levels between these strains $\left(\mathrm{F}_{(1,34)}=0.236, p<0.63\right)$.

\section{Genome Scan}

Table 2 lists the results of the genome scan and indicates that six chromosomes had at least one microsatellite marker

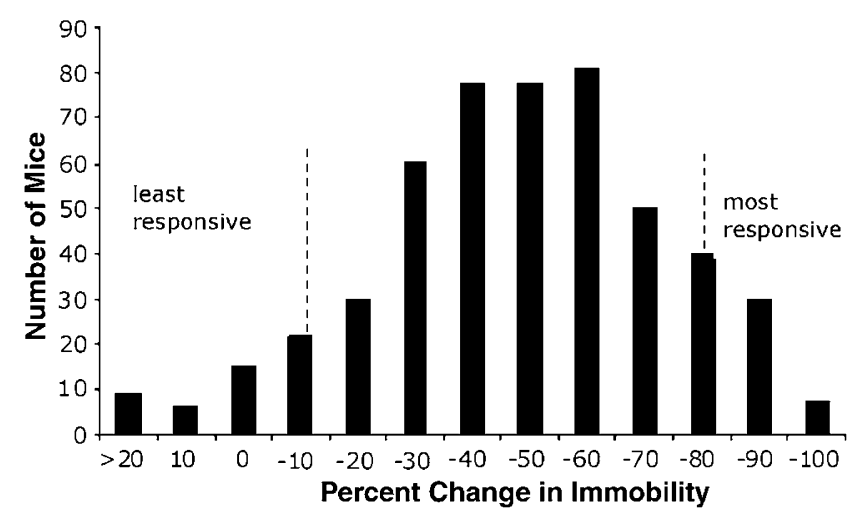

Figure 2 Distribution of citalopram sensitivity scores for 506 F2 mice treated with $20 \mathrm{mg} / \mathrm{kg}$ citalopram in the TST. The number of animals falling into defined ranges of percent change in immobility is shown. Dotted vertical lines indicate the phenotypically extreme mice that were selected for QTL genotyping.

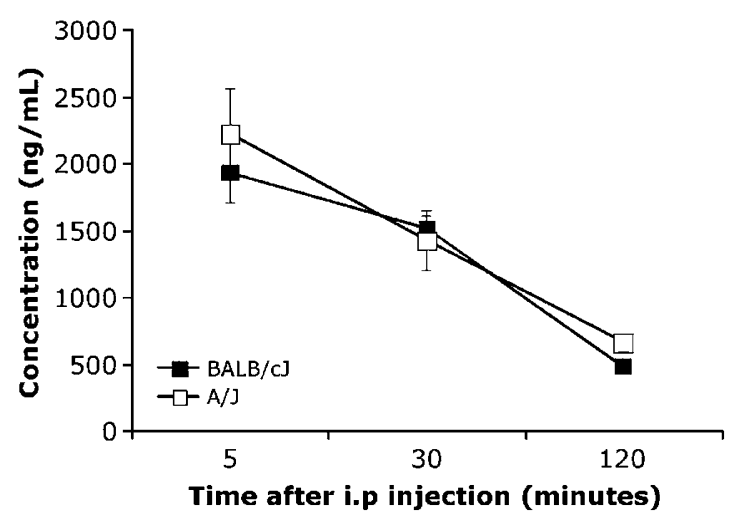

Figure 3 Plasma concentrations of citalopram over time after i.p. injection of $20 \mathrm{mg} / \mathrm{kg}$ in BALB/c and $\mathrm{A} / \mathrm{J}$ mice. Each group was composed of six animals. Values represent mean \pm SEM.

with a regression $p$-value $<0.05$. Chromosome 19 stood out among the other chromosomes in having three consecutive markers with significant $p$-values (D19Mit117, D19Mit025, and D19Mit006) and one marker (D19Mit006) with a highly significant $p$-value $(p=0.00101)$. The genotyping of two additional intermediate markers (D19Mit105 and D19Mit071) revealed higher LRS scores, particularly at marker D19Mit071, a site that was more highly correlated with the citalopram response ( $p=0.00012$ for D19Mit071). The LRS for the chromosome 19 QTL (18.0) exceeded the threshold for significant linkage as determined by permutation testing (16.5), while the LRS scores for the QTLs on chromosome 7 and 12 (11.5 and 11.2, respectively) exceed the criteria for suggestive linkage (9.5). No epistatic interactions between any of these loci were detected. The chromosome 19 QTL was estimated to explain $18 \%$ of the genetic variance in citalopram response scores between the parental strains, while the suggestive QTLs on chromosomes 7 and 12 explained 12 and $11 \%$, respectively. The chromosome 19 QTL resulted from an over-representation of the $\mathrm{BALB} / \mathrm{cJ}$ allele in the most responsive $\mathrm{F}_{2}$ mice relative to the least responsive $\mathrm{F}_{2}$ mice. The chromosome $7 \mathrm{QTL}$, however, displayed the opposite pattern, with the $\mathrm{A} / \mathrm{J}$ allele over-represented in the most responsive $F_{2}$ mice. The 
Table 2 Genome Scan: Microsatellite Markers with p-Values $<0.05$

\begin{tabular}{|c|c|c|c|c|c|c|}
\hline Chromosome & Marker & cM position & $p$-value & $\%$ Variance & LRS statistic & Over-represented in sensitive mice \\
\hline \multirow[t]{2}{*}{2} & D02Mit080 & 10.0 & 0.03436 & 7 & 6.7 & A/J allele \\
\hline & D02Mit370 & 27.3 & 0.04454 & 7 & 6.2 & A/J allele \\
\hline 4 & D04Mit254 & 82.5 & 0.01994 & 8 & 7.8 & A/J allele \\
\hline 12 & DI2Mit I 8 & 45.0 & 0.00365 & 11 & 11.2 & Homozygotes \\
\hline 15 & DI5Mit|44 & 32.2 & 0.01677 & 9 & 8.2 & $\mathrm{BALB} / \mathrm{c}$ J allele \\
\hline 19 & DI9Mit006 & 55.0 & 0.00101 & 14 & 13.8 & $\mathrm{BALB} / \mathrm{c}$ J allele \\
\hline
\end{tabular}

Marker regression of the genotypes for the phenotypically extreme F2 mice under a free regression model was performed using QTX software. Listed are the chromosomal and centimorgan (CM) position of each marker, p-value obtained, percent variance in the F2 population accounted for, likelihood ratio statistic (LRS), and which marker allele was over-represented in the citalopram-sensitive F2 mice. LRS thresholds: 9.5 (suggestive), 16.5 (significant), and 26.4 (highly significant).

chromosome 12 QTL was also unique, resulting from an over-representation of both $\mathrm{BALB} / \mathrm{cJ}$ and $\mathrm{A} / \mathrm{J}$ homozygotes in the most responsive $\mathrm{F}_{2}$ mice.

Each $F_{2}$ mouse was tested once with saline and once with citalopram, allowing for the QTL analysis of not only citalopram responsiveness but also baseline TST immobility behavior. The baseline immobility for the 46 most responsive $\mathrm{F}_{2}$ mice (mean \pm standard deviation $=139 \pm 34 \mathrm{~s}$ ) did not differ from that of the 46 least responsive $\mathrm{F}_{2}$ mice $(142 \pm 32 \mathrm{~s})$. A genome scan for QTL regulating baseline immobility in the subset of $92 \mathrm{~F}_{2}$ mice failed to identify any microsatellite marker with a regression $p$-value $<0.05$. These results demonstrate that the large differences in citalopram responsiveness observed in this subset are not related to baseline immobility behavior, but are specific for the drug response.

Table 3 is a list of candidate genes that are located within $20 \mathrm{cM}$ of a significant marker according to the Mouse Genome Informatics database found on The Jackson Laboratory website (www.informatics.jax.org). Candidate genes were chosen by virtue of being expressed in the brain and known to affect behavior and, in some cases, antidepressant mechanisms. A number of genes related to monoamines, particularly norepinephrine, were located near significant markers.

\section{Candidate Gene Sequencing}

Figure 4 shows the interval mapping results for chromosome 19. The LRS scores toward the distal end of the chromosome meet and exceed the threshold needed for a significant QTL. There are a total of 19 genes, including 17 known genes and two uncharacterized cDNAs, located within in the QTL peak region of $50-55 \mathrm{cM}$, according to the Mouse Genome Informatics database (see Table 4).
Three of these genes were selected for comparative sequence analaysis: alpha $2 \mathrm{a}$ adrenergic receptor (adra2a), beta 1 adrenergic receptor (adrb1), and vesicular monoamine transporter 2 (VMAT2, slc18a2). Sequencing of the protein-coding regions for these three candidate genes in $\mathrm{BALB} / \mathrm{cJ}$ and $\mathrm{A} / \mathrm{J}$ mice yielded no variants in adra2a or $a d r b 1$. However, four single-nucleotide polymorphisms (SNPs) between the $\mathrm{BALB} / \mathrm{cJ}$ and $\mathrm{A} / \mathrm{J}$ strains were discovered in VMAT2, including two that alter amino-acid sequence (350 T $>C$ (Leu117Pro) and $1513 \mathrm{~T}>\mathrm{C}$ (Ser505Pro)). Phylogenetic analysis of VMAT2 amino-acid sequences from different species revealed that these two mis-sense polymorphisms exist in highly conserved regions of the protein (see Figure 5). For the Leu117Pro polymorphism, BALB/cJ mice share the human and rat allele (proline), while for the Ser505Pro polymorphism, A/J mice share the human and rat allele (serine).

\section{DISCUSSION}

A QTL mapping study was undertaken using murine strains that were phenotypically divergent on the antidepressant response to citalopram in the TST, with the ultimate goal being to isolate genetic polymorphisms contributing to the strain difference and thus identify candidate genes for human pharmacogenetic studies of SSRI response. Inbred rodent strains show substantial variability in baseline responses to antidepressant tests and behavioral responses to antidepressant administration (for a review, see Introduction). Aside from their substantial response to citalopram in the TST (Crowley et al, 2005), the BALB/cJ strain was selected because these mice are known to be highly emotional, or anxious, relative to other strains in many classical behavioral tests, including the open field test (Kim et al, 2002), the light/dark test (Griebel et al, 2000; 
Table 3 Candidate Genes within 20 cM of Significant Markers

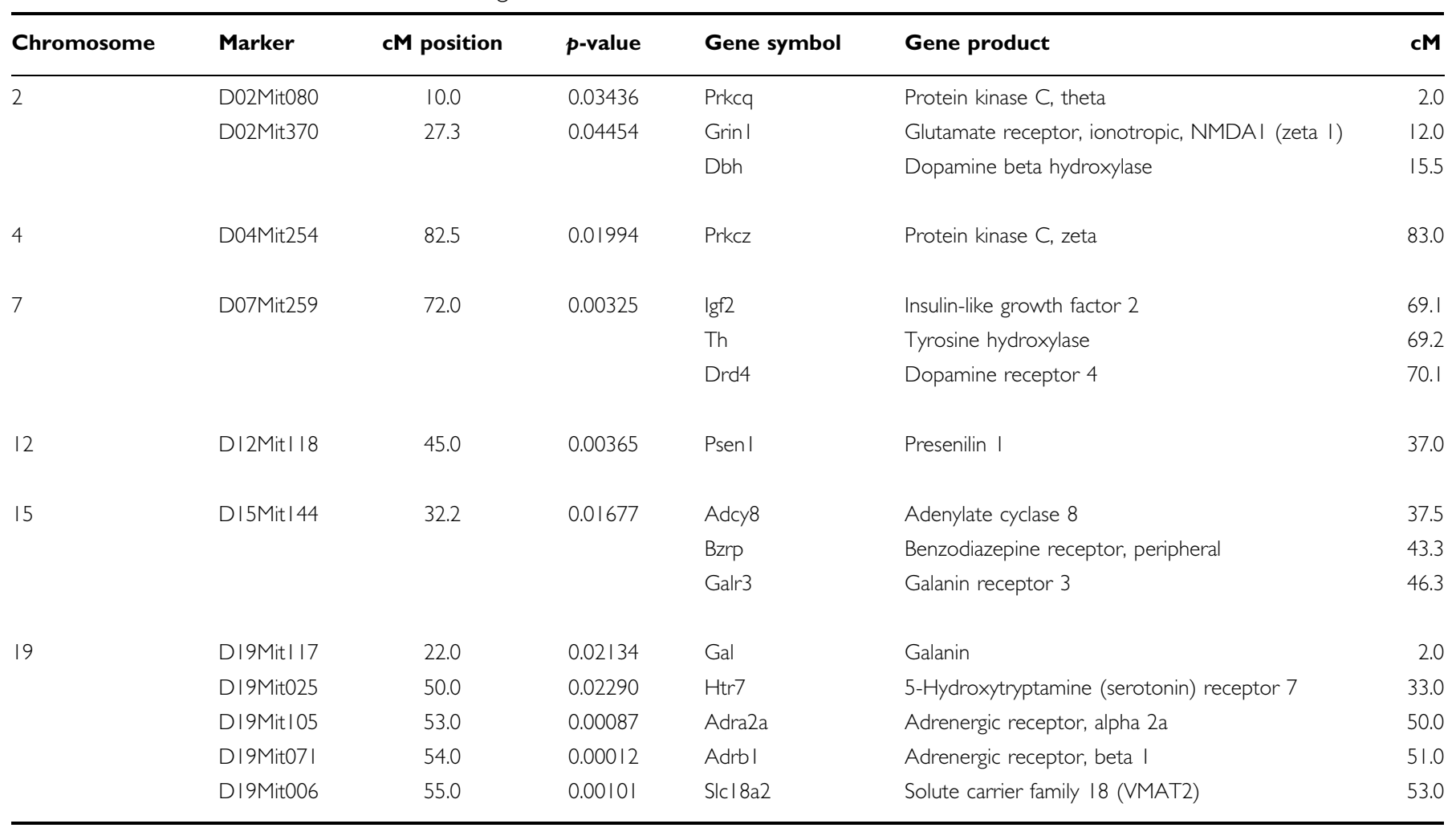

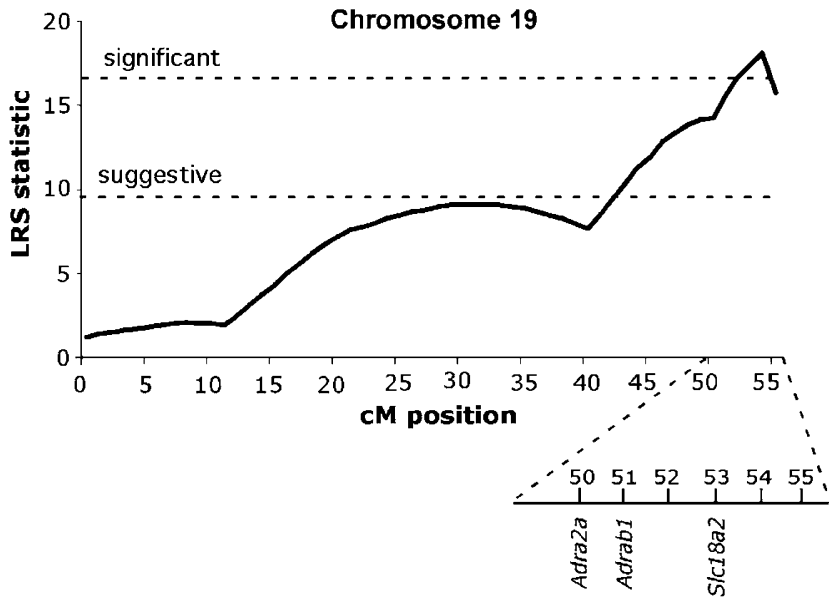

Figure 4 Interval mapping of a QTL on chromosome 19 influencing response to citalopram in the TST. Dotted lines indicate the threshold LRS statistics needed to meet criteria for suggestive and significant QTL as defined by permutation testing. Three candidate genes within the QTL selected for sequence analysis were those encoding the alpha $2 \mathrm{a}$ adrenergic receptor (Adra2a), beta I adrenergic receptor (Adrlb), and vesicular monoamine transporter 2 (S/c/8a2).

Bouwknecht and Paylor, 2002), free-exploration tests (Kopp et al, 1999; Tang et al, 2002; Yilmazer-Hanke et al, 2003), the novel object test (Tang et al, 2002), and the elevated plus maze (Kim et al, 2002). The A/J mouse strain was selected because these mice: (1) were relatively nonresponsive to citalopram in the TST (Crowley et al, 2005), (2) did not differ from $B A L B / c J$ mice in baseline TST immobility, and (3) resembled the $B A L B / c J$ strain in the open field test, showing high levels of anxiety and defecation (Crawley et al, 1997). The different responses to citalopram between BALB/ cJ and A/J mice in the TST appeared similar to differences these strains showed in the effects of the SSRI fluoxetine in the FST, a second antidepressant test (Lucki et al, 2001). However, Cervo et al (2005) reported recently that BALB/c mice responded relatively poorly to citalopram in the FST. This characterization could have resulted from methodological differences between laboratories in conducting and scoring the FST. We recently compared the effects of $5 \mathrm{mg} / \mathrm{kg}$ citalopram in the FST between $\mathrm{BALB} / \mathrm{cJ}$ and $\mathrm{A} / \mathrm{J}$ mice using a computer-scored version of the mouse FST (Crowley et al, 2004). Citalopram produced a significant $33 \%$ reduction of immobility in $\mathrm{BALB} / \mathrm{cJ}$ mice (mean immobility (sec) \pm 1 SEM: saline $199 \pm 17$, citalopram $\left.133 \pm 8 ; t_{17}=3.12, p=0.003\right)$, whereas the drug did not change immobility significantly in A/J mice (saline $193 \pm 6$, citalopram $200 \pm 8 ; t_{18}=0.21, p=0.50$; Crowley and Lucki, unpublished data). Thus, the differences in citalopram response between $B A L B / C J$ and $A / J$ mice shown in the TST do generalize to a second test for antidepressants, the FST.

The goal of this study was to identify genetic loci regulating variance between $\mathrm{BALB} / \mathrm{cJ}$ and $\mathrm{A} / \mathrm{J}$ mice in the response to citalopram in the TST using a QTL analysis. The antidepressant-like effects of citalopram in the TST were not correlated with plasma levels of citalopram, changes in locomotor activity, or deprivation-induced feeding behavior in $\mathrm{BALB} / \mathrm{cJ}$ or $\mathrm{A} / \mathrm{J}$ mice, suggesting that the patterns of sensitivity to citalopram were behaviorally specific (Crowley et al, 2005). The QTL analysis identified three murine loci that, collectively, accounted for more than $40 \%$ of the genetic variance between $\mathrm{BALB} / \mathrm{cJ}$ and $\mathrm{A} / \mathrm{J}$ mice in the 
response to citalopram in the TST. The chromosome 19 QTL resulted from an over-representation of the BALB/cJ allele in the most responsive $F_{2}$ mice relative to the least responsive $\mathrm{F}_{2}$ mice. This indicates that $\mathrm{BALB} / \mathrm{cJ}$ mice possess an allele(s) in this region that caused increased responsiveness to citalopram, and/or that $\mathrm{A} / \mathrm{J}$ mice possess an allele(s) that caused decreased responsiveness to the drug.

A total of 19 genes reside in the peak region of the chromosome 19 QTL. Three of these genes (adra2a, adrb1, and slc18a2 (VMAT2)) stood out among the others as being expressed in the brain and known to be involved in monoamine neurotransmission, which is clearly relevant to the mechanism of action of SSRIs. Recent clinical findings suggest that the alpha $2 \mathrm{~A}$ adrenergic receptor may play a protective role in some forms of depression and anxiety and that the antidepressant effects of imipramine may be mediated by the alpha $2 \mathrm{~A}$ receptor (Schramm et al, 2001).

Table 4 Genes Located within the Chromosome 19 QTL Peak Region

\begin{tabular}{|c|c|c|}
\hline $\begin{array}{l}\text { cM } \\
\text { position }\end{array}$ & $\begin{array}{l}\text { Gene } \\
\text { symbol }\end{array}$ & Gene product \\
\hline 50.0 & Adra2a & Adrenergic receptor, alpha $2 \mathrm{a}$ \\
\hline 50.0 & Casp7 & Caspase 7 \\
\hline 50.0 & D/9Wsul62e & $\begin{array}{l}\text { DNA segment, Chr 19, Wayne State } \\
\text { University 162, expressed }\end{array}$ \\
\hline 50.0 & Myo $|f-r s|$ & Myosin IF, related sequence I \\
\hline 50.0 & $\operatorname{Prd} \times 3$ & Peroxiredoxin 3 \\
\hline 51.0 & Adrb I & Adrenergic receptor, beta I \\
\hline 51.0 & Csf2ra & $\begin{array}{l}\text { Colony-stimulating factor } 2 \text { receptor, alpha, } \\
\text { low-affinity (granulocyte-macrophage) }\end{array}$ \\
\hline 52.0 & Gpam & $\begin{array}{l}\text { Glycerol-3-phosphate acyltransferase, } \\
\text { mitochondrial }\end{array}$ \\
\hline 52.0 & Tectb & Tectorin beta \\
\hline 53.0 & Ablim I & Actin-binding LIM protein I \\
\hline 53.0 & Gucy2g & Guanylate cyclase $2 g$ \\
\hline 53.0 & Slcl $8 a 2$ & $\begin{array}{l}\text { Solute carrier family I } 8 \text { (vesicular } \\
\text { monoamine), member } 2\end{array}$ \\
\hline 53.0 & Tcfll2 & $\begin{array}{l}\text { Transcription factor 7-like 2, T-cell specific, } \\
\text { HMG-box }\end{array}$ \\
\hline 53.3 & Nrap & Nebulin-related anchoring protein \\
\hline 53.5 & $E m \times 2$ & Empty spiracles homolog 2 (Drosophila) \\
\hline 53.5 & Vaxl & Ventral anterior homeobox-containing gene I \\
\hline 54.0 & Lamrl-rs7 & $\begin{array}{l}\text { Laminin receptor I (ribosomal protein SA), } \\
\text { related sequence } 7\end{array}$ \\
\hline 55.0 & Gprk5 & G protein-coupled receptor kinase 5 \\
\hline 57.0 & D/9Ertd737e & $\begin{array}{l}\text { DNA segment, Chr 19, ERATO Doi } 737 \text {, } \\
\text { expressed }\end{array}$ \\
\hline
\end{tabular}

The beta-1 adrenergic receptor is well known to show altered density and/or sensitivity in depression and is downregulated in several brain regions after long-term treatment with certain antidepressants (Ordway et al, 1988; Manji and Lenox, 2000; Banerjee et al, 1977). A recent clinical study found a tendency for a relationship between an adrb1 polymorphism and a better and more rapid response to antidepressant treatment (Zill et al, 2003).

VMAT2 is a neuronally expressed subtype of the vesicular monoamine transporter responsible for loading synaptic vesicles with the monoamine neurotransmitters serotonin, norepinephrine, dopamine, and histamine (Liu et al, 1992; Peter et al, 1994; Erickson et al, 1992, 1996). Mice lacking both copies of the VMAT2 gene die during development, but heterozygotes survive and show reduced amphetamineconditioned reward, enhanced amphetamine and cocaineinduced locomotion, and enhanced MPTP toxicity (Takahashi et al, 1997; Wang et al, 1997). We hypothesized that sequence variants in the regions of the mouse genes encoding VMAT2, the alpha 2A adrenergic receptor, and/or beta-1 adrenergic receptor might explain the QTL and thus the differential effects of citalopram in the parental strains. Sequencing of the coding regions revealed no polymorphisms in the adrenergic receptor genes. However, two mis-sense SNPs in the gene for VMAT2 (Leu117Pro and Ser505Pro) were revealed by sequencing. Phylogenetic analysis of VMAT2 amino-acid sequences from several species indicated that both mis-sense polymorphisms exist in regions of high conservation, and thus may impact function. Furthermore, both polymorphisms involve changes to proline, which by virtue of its ring structure, often alters secondary structure by interrupting an alphahelix (Voet and Voet, 2004).

It is intriguing to speculate that the polymorphic differences in the VMAT2 gene could be associated with the antidepressant response to citalopram. Further studies can determine whether these polymorphisms produce functional effects upon VMAT2 activity and if this gene truly explains the QTL. Confirmation that this gene underlies the QTL would make VMAT2 a very attractive gene for human pharmacogenetic studies of SSRI response. A number of polymorphisms have been identified in the human VMAT2 gene, including SNPs in the promoter region that are known to alter transcription (Lin et al, 2005). In a gene association study, a set of these promoter SNPs were found to represent a protective factor against alcoholism (Lin et al, 2005). Two rare mis-coding variants of the VMAT2 gene showed minimal effects on transport function but did alter substrate recognition and inhibition by reserpine (Burman et al, 2004). A search of the publicdomain archive of SNPs, dbSNP (www.ncbi.nlm.nih.gov/ projects/SNP), revealed 223 SNPs in the human VMAT2 gene. Some of these polymorphisms of the VMAT2 gene

\begin{tabular}{|c|c|c|}
\hline Human & 116 & TNASAVPSDCPSEDK........ QNNIQSYPIGEDEE \\
\hline Chimpanzee & 108 & TNASAVPSDCPSEDK........ QNNIQSYPIGDDEE \\
\hline Cow & 111 & TNSSSASSDCPSEDK. . . . . . QNSSQSHPIGEDEE \\
\hline Rat & 110 & AN-TTVPSDCPSEDR. . . . . . QNNVQSYPIGDDEE \\
\hline Mouse: $\mathrm{BALB} / \mathrm{CJ}$ & 112 & TN-TTVPPDCPSEDK.... \\
\hline Mouse: $\mathrm{A} / \mathrm{J}$ & 112 & TN-TTVLPDCPSEDK. . . . . . \\
\hline
\end{tabular}

Figure 5 Phylogenetic analysis of VMAT2 amino-acid sequences from different species. The positions of two mis-coding polymorphisms (Leu I 7Pro and Ser505Pro) between the BALB/CJ and A/J inbred mouse strains are shown in bold. 
may be shown to regulate transporter activity and could be studied in populations of SSRI responders and nonresponders, similar to other genes that have been shown to influence antidepressant response.

A large body of work by Rehavi and co-workers has demonstrated that exposure to stress, chronic drug treatment, or presence of a psychiatric condition can alter the expression of VMAT2, primarily at the protein level. In rats, repeated swim stress produced a downregulation of VMAT2 protein in the nucleus accumbens and striatum, as measured by $\left[{ }^{3} \mathrm{H}\right]$ dihydrotetrabenazine binding (Zucker et al, 2005). A rat genetic model of depression, the Flinderssensitive line (FSL), also displays decreased limbic VMAT2 protein levels relative to its control (Schwartz et al, 2003). These data suggest the possibility that decreased VMAT2 causes reduced monoamine transmission and this might be involved in the depressive features and anhedonia seen in swim-stressed or FSL rats. Chronic treatment of rats with the antipsychotic clozapine (Rehavi et al, 2002) or the mood stabilizer lithium (Zucker et al, 2001a, b) has been shown to increase VMAT2 protein levels, while chronic treatment with the dopamine precursor L-DOPA (Zucker et al, 2001a,b), or the hormones progesterone and estradiol decrease VMAT2 protein (Rehavi et al, 1998). Interestingly, acute treatment of rats with the VMAT2 inhibitor reserpine, or chronic treatment with the SSRI paroxetine, did not alter the levels of VMAT2 protein or mRNA (Vilpoux et al, 2000). Using human platelets as a peripheral measure for VMAT2 expression, Rehavi and co-workers found increased platelet VMAT2 density in depressed (Zucker et al, 2002a) and schizophrenic patients (Zucker et al, 2002b), and decreased VMAT2 density in children with attention deficit/hyperactivity disorder (Toren et al, 2005) and habitual smokers (Schwartz et al, 2005). These preclinical and clinical studies indicate that genetic polymorphisms in VMAT2 (slc18a2) could be associated with drug treatment or disease state, and perhaps may regulate the antidepressant response to citalopram as shown in this study using the mouse TST.

Genetic analysis of the antidepressant-like response to citalopram in mice in this study showed that this behavioral response is a heritable trait. In the F2 population of mice, approximately half the total variance in citalopram response scores was the result of genetic factors, with a heritability estimate of 0.53 . Three QTL were mapped that account for roughly $40 \%$ of this genetic variation. In the same F2 population, however, no loci regulating baseline immobility were identified, demonstrating the behavioral and genetic specificity of the trait. This is an important point because inbred strains do show significant differences in baseline immobility in the TST (Crowley et al, 2005; Yoshikawa et al, 2002) and QTL regulating baseline immobility have been mapped (Yoshikawa et al, 2002).

The chromosome 7 QTL displayed an opposite pattern from the chromosome 19 QTL, with the A/J allele overrepresented in the most responsive $\mathrm{F}_{2}$ mice. This indicates that $\mathrm{A} / \mathrm{J}$ mice possessed an allele(s) in this region that increased responsiveness to citalopram, or $\mathrm{BALB} / \mathrm{cJ}$ mice possessed an allele(s) that decreased responsiveness to the drug. This may seem counterintuitive, given that A/J mice are the nonresponsive strain. However, an inbred mouse strain may have alleles that have opposing effects on a phenotype; that is, mice may possess alleles that cause decreased sensitivity to citalopram as well as alleles that cause increased sensitivity to citalopram, the net effect of which are to make A/J relatively less sensitive to citalopram. Likewise, $\mathrm{BALB} / \mathrm{cJ}$ mice may possess negative modifier loci, even though positive modifier loci predominate when the whole genome is intact. The chromosome 12 QTL was somewhat unusual. It resulted from an over-representation of both $\mathrm{BALB} / \mathrm{cJ}$ and $\mathrm{A} / \mathrm{J}$ homozygotes in the most responsive $\mathrm{F}_{2}$ mice and over-representation of heterozygotes in the least responsive $\mathrm{F}_{2}$ mice. This may be a case of inbreeding depression (Burke and Arnold, 2001), in which there is an increased strength of certain characteristics of genes in hybrids. In this study, the response to citalopram seemed to be diminished in the heterozygous $\mathrm{F}_{2}$ mice.

Zhang et al (2004) reported a functional SNP (C1473G) in the mouse tryptophan hydroxylase 2 gene (Tph2), with the substitution of Pro447 with Arg447, that leads to decreased serotonin levels when expressed in PC12 cells. Moreover, in $\mathrm{BALB} / \mathrm{CJ}$ and $\mathrm{DBA} / 2$ mice that were homozygous for the $1473 \mathrm{G}$ allele, brain serotonin tissue content and synthesis were reduced in comparison to $\mathrm{C} 57 \mathrm{Bl} / 6$ and $129 \mathrm{X} 1 / \mathrm{SvJ}$ mice that were homozygous for the $1473 \mathrm{C}$ allele. The authors noted that this strain distribution paralleled responsiveness to fluoxetine in the FST (Lucki et al, 2001) and suggested that it may be causally related. However, this association does not extend to the strains compared in this study. The SSRI nonresponsive $\mathrm{A} / \mathrm{J}$ mouse strain and the SSRI responsive $\mathrm{BALB} / \mathrm{cJ}$ strain share the $\mathrm{G}$ allele (hyporesponsive) for the mouse tph2 gene (Crowley et al, 2005). Examination of the citalopram TST response in a larger number of strains is likely to reveal how variations in the tph2 gene, or other specific genes, are capable of regulating the response to different types of antidepressant drugs.

In conclusion, QTL mapping has identified the chromosomal location of genes that contribute to the differential response to citalopram in the TST between BALB/cJ and A/J mice. Interval mapping revealed three loci on chromosomes 7,12 , and 19 that are responsible for more than $40 \%$ of the genetic variance observed between the two parental strains. Candidate gene analysis identified two mis-sense polymorphisms in the gene encoding vesicular monoamine transporter 2 that may underlie the chromosome 19 QTL.

\section{ACKNOWLEDGEMENTS}

We thank Kristin A Kaercher and Geena Mary V Sankoorikal for technical assistance. This research was supported by USPHS grants MH48152 (IL), MH14652 (IL, JJC), and K08MH068586 (ESB), and a Burroughs Wellcome Fund Career Award in the Biomedical Sciences (ESB).

\section{REFERENCES}

Bai F, Li X, Clay M, Lindstrom T, Skolnick P (2001). Intra- and interstrain differences in models of 'behavioral despair'. Pharm Biochem Behav 70: 187-192.

Banerjee SP, Kung LS, Riggi SJ, Chanda SK (1977). Development of beta-adrenergic receptor subsensitivity by antidepressants. Nature 268: 455-456.

Bouwknecht JA, Paylor R (2002). Behavioral and physiological mouse assays for anxiety: a survey in nine mouse strains. Behav Brain Res 136: 489-501. 
Burke JM, Arnold ML (2001). Genetics and the fitness of hybrids. Annu Rev Genet 35: 31-52.

Burman J, Tran CH, Glatt C, Freimer NB, Edwards RH (2004). The effect of rare human sequence variants on the function of vesicular monoamine transporter 2. Pharmacogenetics 14: 587-594.

Cervo L, Canetta A, Calcagno E, Burbassi S, Sacchetti G, Caccia S et al (2005). Genotype-dependent activity of tryptophan hydroxylase-2 determines the response to citalopram in a mouse model of depression. J Neurosci 25: 8165-8172.

Crawley JN, Belknap JK, Collins A, Crabbe JC, Frankel W, Henderson $\mathrm{N}$ et al (1997). Behavioral phenotypes of inbred mouse strains: implications and recommendations for molecular studies. Psychopharmacology 132: 107-124.

Crowley JJ, Blendy JA, Lucki I (2005). Strain-dependent antidepressant-like effects of citalopram in the mouse tail suspension test. Psychopharmacology 183: 257-264.

Crowley JJ, Jones MD, O’Leary OF, Lucki I (2004). Automated tests for measuring the effects of antidepressants in mice. Pharmacol Biochem Behav 78: 269-274.

Crowley JJ, Lucki I (2005). Opportunities to discover genes regulating depression and antidepressant response from rodent behavioral genetics. Curr Pharm Des 11: 157-169.

Cryan JF, Markou A, Lucki I (2002). Assessing antidepressant activity in rodents: recent developments and future needs. Trends Pharmacol Sci 23: 238-245.

Cryan JF, Mombereau C, Vassout A (2005). The tail suspension test as a model for assessing antidepressant activity: review of pharmacological and genetic studies in mice. Neurosci Biobehav Rev 29: 571-625.

Erickson JD, Eiden LE, Hoffman BJ (1992). Expression cloning of a reserpine-sensitive vesicular monoamine transporter. Proc Natl Acad Sci USA 89: 10993-10997.

Erickson JD, Schafer MK, Bonner TI, Eiden LE, Weihe E (1996). Distinct pharmacological properties and distribution in neurons and endocrine cells of two isoforms of the human vesicular monoamine transporter. Proc Natl Acad Sci USA 93: 5166-5171.

Flint J, Valdar W, Shifman S, Mott R (2005). Strategies for mapping and cloning quantitative trait genes in rodents. Nat Rev Genet 6: 271-286.

Griebel G, Belzung C, Perrault G, Sanger DJ (2000). Differences in anxiety-related behaviours and in sensitivity to diazepam in inbred and outbred strains of mice. Psychopharmacology 148: $164-170$

Kim S, Lee S, Ryu S, Suk J, Park C (2002). Comparative analysis of the anxiety-related behaviors in four inbred mice. Behav Process 60: 181-190.

Kopp C, Vogel E, Rettori MC, Delagrange P, Renard P, Lesieur D et al (1999). Antagonistic effects of S 22153, a new mtl and MT2 receptor ligand, on the neophobia-reducing properties of melatonin in BALB/c mice. Pharmacol Biochem Behav 64: $131-136$.

Lahiri DK, Nurnberger Jr JI (1991). A rapid non-enzymatic method for the preparation of HMW DNA from blood for RFLP studies. Nucleic Acids Res 19: 5444.

Lander ES, Botstein D (1989). Mapping mendelian factors underlying quantitative traits using RFLP linkage maps. Genetics 121: 185-199.

Lin Z, Walther D, Yu XY, Li S, Drgon T, Uhl GR (2005). SLC18A2 promoter haplotypes and identification of a novel protective factor against alcoholism. Hum Mol Genet 14: 1393-1404.

Liu X, Gershenfeld HK (2001). Genetic differences in the tail-suspension test and its relationship to imipramine response among 11 inbred strains of mice. Biol Psychiatry 49: $575-581$.

Liu X, Gershenfeld HK (2003). An exploratory factor analysis of the tail suspension test in 12 inbred strains of mice and an F2 intercross. Brain Res Bull 60: 223-231.
Liu Y, Peter D, Roghani A, Schuldiner S, Prive GG, Eisenberg D et al (1992). A cDNA that suppresses MPP+ toxicity encodes a vesicular amine transporter. Cell 70: 539-551.

Lucki I, Dalvi A, Mayorga AJ (2001). Sensitivity to the effects of pharmacologically selective antidepressants in different strains of mice. Psychopharmacology 155: 315-322.

Manji HK, Lenox RH (2000). Signaling: cellular insights into the pathophysiology of bipolar disorder. Biol Psychiatry 48: 518-530.

Manly KF, Cudmore Jr RH, Meer JM (2001). Map Manager QTX, cross-platform software for genetic mapping. Mamm Genome 12: $930-932$.

Nelson JC (1999). A review of the efficacy of serotonergic and noradrenergic reuptake inhibitors for treatment of major depression. Biol Psychiatry 46: 1301-1308.

Ordway GA, Gambarana C, Frazer A (1988). Quantitative autoradiography of central beta adrenoceptor subtypes: comparison of the effects of chronic treatment with desipramine or centrally administered L-isoproterenol. J Pharmacol Exp Ther 247: 379-389.

Perrault GH, Morel E, Zivkovic B, Sanger DJ (1992). Activity of litoxetine and other serotonin uptake inhibitors in the tail suspension test in mice. Pharmacol Biochem Behav 42: 45-47.

Peter D, Jimenez J, Liu Y, Kim J, Edwards RH (1994). The chromaffin granule and synaptic vesicle amine transporters differ in substrate recognition and sensitivity to inhibitors. J Biol Chem 269: 7231-7237.

Rehavi M, Goldin M, Roz N, Weizman A (1998). Regulation of rat brain vesicular monoamine transporter by chronic treatment with ovarian hormones. Brain Res Mol Brain Res 57: 31-37.

Rehavi M, Roz N, Weizman A (2002). Chronic clozapine, but not haloperidol, treatment affects rat brain vesicular monoamine transporter 2. Eur Neuropsychopharmacol 12: 261-268.

Rippoll N, David DJ, Dailly E, Hascoet M, Bourin M (2003). Antidepressant-like effects in various mice strains in the tail suspension test. Behav Brain Res 143: 193-200.

Schramm NL, McDonald MP, Limbird LE (2001). The alpha(2a)adrenergic receptor plays a protective role in mouse behavioral models of depression and anxiety. J Neurosci 21: 4875-4882.

Schwartz K, Weizman A, Rehavi M (2005). Decreased platelet vesicular monoamine transporter density in habitual smokers. Eur Neuropsychopharmacol 15: 235-238.

Schwartz K, Yadid G, Weizman A, Rehavi M (2003). Decreased limbic vesicular monoamine transporter 2 in a genetic rat model of depression. Brain Res 965: 174-179.

Serretti A, Artioli P (2004). The pharmacogenomics of selective serotonin reuptake inhibitors. Pharmacogenomics J 4: 233-244.

Steru L, Chermat R, Thierry B, Mico JA, Lenegre A, Steru M et al (1987). The automated tail suspension test: a computerized device which differentiates psychotropic drugs. Prog Neuropsychopharmacol Biol Psychiatry 11: 659-671.

Steru L, Chermat R, Thierry B, Simon P (1985). The tail suspension test: a new method for screening antidepressants in mice. Psychopharmacology 85: 367-370.

Takahashi N, Miner LL, Sora I, Ujike H, Revay RS, Kostic V et al (1997). VMAT2 knockout mice: heterozygotes display reduced amphetamine-conditioned reward, enhanced amphetamine locomotion, and enhanced MPTP toxicity. Proc Natl Acad Sci USA 94: 9938-9943.

Tang X, Orchard SM, Sanford LD (2002). Home cage activity and behavioral performance in inbred and hybrid mice. Behav Brain Res 136: 555-569.

Teste JF, Martin I, Rinjard P (1990). Electrotherapy in mice: dopaminergic and noradrenergic effects in the tail suspension test. Fundam Clin Pharmacol 4: 39-47.

Teste JF, Pelsey-Johann I, Decelle T, Boulu RG (1993). Antiimmobility activity of different antidepressant drugs using the tail suspension test in normal or reserpinized mice. Fundam Clin Pharmacol 7: 219-226. 
Toren P, Rehavi M, Luski A, Roz N, Laor N, Lask M et al (2005). Decreased platelet vesicular monoamine transporter density in children and adolescents with attention deficit/hyperactivity disorder. Eur Neuropsychopharmacol 15: 159-162.

Vilpoux C, Leroux-Nicollet I, Naudon L, Raisman-Vozari R, Costentin J (2000). Reserpine or chronic paroxetine treatments do not modify the vesicular monoamine transporter 2 expression in serotonin-containing regions of the rat brain. Neuropharmacology 39: 1075-1082.

Voet D, Voet J (2004). Biochemistry, 3rd edn. J Wiley \& Sons: Hoboken, New Jersey.

Wang YM, Gainetdinov RR, Fumagalli F, Xu F, Jones SR, Bock CB et al (1997). Knockout of the vesicular monoamine transporter 2 gene results in neonatal death and supersensitivity to cocaine and amphetamine. Neuron 19: 1285-1296.

Waterston RH, Lindblad-Toh K, Birney E, Rogers J, Abril JF, Agarwal $\mathrm{P}$ et al (2002). Initial sequencing and comparative analysis of the mouse genome. Nature 420: 520-562.

Wehner JM, Radcliffe RA, Bowers BJ (2001). Quantitative genetics and mouse behavior. Annu Rev Neurosci 24: 845-867.

Yilmazer-Hanke DM, Roskoden T, Zilles K, Schwegler H (2003). Anxiety-related behavior and densities of glutamate, GABAA, acetylcholine and serotonin receptors in the amygdala of seven inbred mouse strains. Behav Brain Res 145: 145-159.

Yoshikawa T, Watanabe A, Ishitsuka Y, Nakaya A, Nakatani $\mathrm{N}$ (2002). Identification of multiple genetic loci linked to the propensity for 'behavioral despair' in mice. Genome Res 12: $357-366$.

Zhang X, Beaulieu JM, Sotnikova TD, Gainetdinov RR, Caron MG (2004). Tryptophan hydroxylase-2 controls brain serotonin synthesis. Science 305: 217.

Zill P, Baghai TC, Engel R, Zwanzger P, Schule C, Minov C et al (2003). Beta-1-adrenergic receptor gene in major depression: influence on antidepressant treatment response. Am J Med Genet B Neuropsychiatr Genet 120: 85-89.

Zucker M, Aviv A, Shelef A, Weizman A, Rehavi M (2002a). Elevated platelet vesicular monoamine transporter density in untreated patients diagnosed with major depression. Psychiatry Res 112: 251-256.

Zucker M, Valevski A, Weizman A, Rehavi M (2002b). Increased platelet vesicular monoamine transporter density in adult schizophrenia patients. Eur Neuropsychopharmacol 12: 343-347.

Zucker M, Weizman A, Harel D, Rehavi M (2001a). Changes in vesicular monoamine transporter (VMAT2) and synaptophysin in rat substantia nigra and prefrontal cortex induced by psychotropic drugs. Neuropsychobiology 44: 187-191.

Zucker M, Weizman A, Rehavi M (2001b). Characterization of high-affinity $[3 \mathrm{H}] \mathrm{TBZOH}$ binding to the human platelet vesicular monoamine transporter. Life Sci 69: 2311-2317.

Zucker M, Weizman A, Rehavi M (2005). Repeated swim stress leads to down-regulation of vesicular monoamine transporter 2 in rat brain nucleus accumbens and striatum. Eur Neuropsychopharmacol 15: 199-201. 